\title{
APLICAÇÃO DE REVESTIMENTO COMESTÍVEL DE QUITOSANA EM BRÓCOLIS MINIMAMENTE PROCESSADO
}

\author{
VÂNIA RIBEIRO DE ARAÚJO* \\ MARIANNE AYUMI SHIRAI**
}

\begin{abstract}
O processamento mínimo oferece praticidade a uma grande variedade de vegetais como os brócolis. Entretanto, este processamento causa um aumento na perecibilidade do produto, pois os danos causados pelo corte ou descascamento deixa o vegetal susceptível a diversas fontes de contaminação microbiológica, além de aumentar a sua taxa de respiração. Neste sentido, coberturas comestíveis a base de biopolímeros estão sendo cada vez mais estudadas com o objetivo de auxiliar na conservação de vegetais minimamente processados. Este trabalho teve como objetivo aplicar o revestimento comestível a base de quitosana em brócolis minimamente processado e avaliar a sua vida útil durante 10 dias de armazenamento refrigerado. Para isso foram realizadas análises físico-químicas e microbiológicas, tais como: cor, $\mathrm{pH}$, perda de massa, teor de ácido ascórbico, contagem de mesófilos e bolores e leveduras. Os brócolis minimamente processados revestidos com quitosana apresentaram menor perda de massa e de ácido ascórbico, além de inibir a multiplicação de bolores e leveduras. Os resultados deste estudo sugerem que a quitosana possui grande potencial para ser aplicada como cobertura comestível em vegetais minimamente processado em escala comercial.
\end{abstract}

PALAVRAS-CHAVE: BIOPOLÍMERO. ATIVIDADE ANTIMICROBIANA. VIDA ÚTIL. ÁCIDO ASCÓRBICO.

\footnotetext{
* Graduanda em Tecnologia de Alimentos, Universidade Tecnológica Federal do Paraná, Campus Campo Mourão, PR (e-mail: vania_arj@hotmail.com)

** Doutora em Ciência de Alimentos, Professor Adjunto, Departamento Acadêmico de Alimentos, Universidade Tecnológica Federal do Paraná, Campus Campo Mourão, PR (e-mail: marianneshirai@utfpr.edu.br)
} 


\section{INTRODUÇÃO}

Os brócolis pertencem à espécie Brassica oleracea $L$. e se destacam pela presença de glucosinolatos, flavonoides, vitaminas C, E e A e pela propriedade antioxidante (PAGE et al., 2001; LEMOINE et al., 2009; VALLEJO; GARCÍA-VIGUERA; TOMÁS-BARBERÁN, 2003). Há cultivares do tipo ramoso e do tipo cabeça, sendo que o tipo ramoso se caracteriza por apresentar grande número de inflorescências pequenas e com botões florais grandes. Já o grupo conhecido como cabeça, apresenta uma inflorescência central mais compacta, com botões florais menores do que os do grupo ramoso (FILGUEIRA, 2000).

Uma forma de diversificar a oferta no mercado e ao mesmo tempo agregar valor aos brócolis seria realizar o seu processamento mínimo. Os vegetais minimamente processados são aqueles que passaram pelas operações de lavagem, seleção, sanitização, descascamento e corte com o objetivo de proporcionar ao consumidor produtos prontos, práticos e com características de frescos (APPENDINI; HOTCHKISS, 2002; CENSI, 2011).

Diferente de grande parte das técnicas de processamento de alimentos, o processamento mínimo causa um aumento na perecibilidade do produto, uma vez que o dano causado pelo corte ou descascamento aumenta a susceptibilidade da ação de fungos e bactérias patogênicas. Além disso, os tecidos fatiados por terem uma maior superfície de exposição e difusão de oxigênio, apresentam maiores taxas de respiração e, consequentemente, maiores alterações fisiológicas e bioquímicas em relação ao tecido inteiro, como aceleração de reações de escurecimento, descoloração de pigmentos externos, mudança de textura e perda nutricional (PORTE; MAIA, 2001; CHITARRA; CHITARRA, 2005).

Uma tecnologia alternativa cada vez mais divulgada e avaliada como um procedimento viável para elevar a vida útil de vegetais minimamente processados é o emprego de coberturas comestíveis. Esses revestimentos não têm como objetivo substituir o uso dos materiais convencionais de embalagens ou mesmo eliminar definitivamente o emprego do frio, mas sim o de apresentar uma atuação funcional e coadjuvante, contribuindo para a preservação da textura e do valor nutricional, reduzindo as trocas gasosas superficiais e a perda ou ganho excessivo de água (ASSIS et al., 2008; ASSIS; BRITTO, 2014; PARK, 2005; TURHAN, 2010).

Entre as matérias-primas empregadas na produção de coberturas comestíveis destacase a quitosana, um polímero biodegradável, biocompatível, geralmente extraído de carapaças de crustáceos e que possui certa atividade antimicrobiana. Diversas pesquisas relatam com sucesso a aplicação de quitosana como cobertura comestível em frutas e hortaliças tanto in natura como minimamente processada (ALVAREZ; PONCE; MOREIRA, 2013; ANSORENA; MARCOVICH; ROURA, 2011; MOREIRA; ROURA, PONCE, 2011; QIU et al., 2013).

Desta forma, o objetivo deste trabalho foi avaliar o efeito da aplicação de cobertura comestível a base de quitosana sobre a vida útil de brócolis minimamente processado.

\section{MATERIAL E MÉTODOS}

\subsection{MATERIAL}

Neste trabalho foi utilizado a quitosana de baixa massa molecular (Sigma Aldrich, Brasil) com $85 \%$ de grau de desacetilação e ácido acético glacial (Dinâmica, São Paulo) para o preparo da solução de recobrimento. Os brócolis (Brassica oleracea $L$. var. italica), as bandejas de poliestireno expandido (isopor) e o filme de policloreto de vinil (PVC) foram adquiridos no comércio de Campo Mourão - PR. 


\subsection{APLICAÇÃO DO RECOBRIMENTO DE QUITOSANA EM BRÓCOLIS MINIMAMENTE PROCESSADO}

A solução de recobrimento foi preparada dissolvendo-se $20 \mathrm{~g}$ de quitosana em um litro de solução de ácido acético $1 \%(\mathrm{v} / \mathrm{v})$. Para completa dispersão da quitosana, a solução foi agitada em agitador magnético por um período de 30 minutos a temperatura ambiente (ANSORENA, MARCOVICH, ROURA, 2011; PARK, DAESCHEL, ZHAO, 2004).

Nos Brócolis do tipo "cabeça" foram realizadas as operações de seleção, lavagem e sanitização com água clorada (100 ppm), remoção da água residual e corte dos floretes. Nos brócolis minimamente processados foram realizados os seguintes tratamentos: a) sem imersão em solução de quitosana (controle); b) imersão em solução ácida de quitosana; c) imersão em solução de ácido acético $1 \%(\mathrm{v} / \mathrm{v})$.

Para o tratamento com quitosana e ácido acético, os floretes de brócolis foram imersos em solução de quitosana ou solução de ácido acético por 3 minutos a temperatura ambiente, drenados, secos a temperatura ambiente e envasados em bandejas de poliestireno expandido com capacidade de $100 \mathrm{~g}$ e recobertos com filmes de PVC. As bandejas contendo brócolis foram armazenadas em refrigerador a $10^{\circ} \mathrm{C}$ e análises físico-químicas e microbiológicas foram realizadas nos tempos 0 , 3,6 e 10 dias. As análises no tempo 0 foram realizadas com os brócolis antes de passarem pelos tratamentos.

\subsection{AVALIAÇÃO DA VIDA ÚTIL DOS BRÓCOLIS MINIMAMENTE PROCESSADOS}

\subsection{1. $\mathrm{pH}$}

A amostra na quantidade de $10 \mathrm{~g}$ foi triturada com $100 \mathrm{~mL}$ de água destilada a $25^{\circ} \mathrm{C}$ em um béquer. $\mathrm{O}$ eletrodo do pHmetro de bancada (Marte Científica, São Paulo) devidamente calibrado, foi inserido na amostra para leitura do pH (IAL, 2008).

\subsubsection{Perda de massa}

As amostras foram pesadas em balança semi-analítica (Marconi, São Paulo) e a perda de massa fresca durante o armazenamento foi determinada conforme a Equação 1 (PEREIRA, et al. 2005):

$$
\% \text { perda de massa fresca }=\left(M_{n} / M_{o}\right) \times 100 \text { (Equação 1) }
$$

Sendo $M_{0}$ a massa no tempo inicial de armazenamento $\left(1^{\circ}\right.$ dia $)$ e $M_{n}$ a massa para os dias posteriores de análise $(n=3,6$ e 10).

\subsubsection{Teor de vitamina C}

Para a determinação do teor de vitamina $C$ foi utilizado o método padrão da AOAC, modificado por Benassi e Antunes (1988). Amostras de brócolis foram homogeneizadas com solução extratora de ácido oxálico $2 \%$ (Dinâmica, São Paulo) em liquidificador e em seguida foi titulada com solução padronizada de 2,6-diclorofenolindofenol 0,01\% (Vetec, São Paulo). Os resultados foram expressos em mg de vitamina C / $100 \mathrm{~g}$ de produto.

\subsubsection{Cor}

A cor foi medida com auxílio do colorímetro (Mini Scan EZ), onde foram tomadas medidas aleatórias da superfície externa dos floretes de brócolis. O colorímetro foi previamente calibrado em placas padrão de cor branco e preto, com fonte de iluminação D65 e ângulo de observação de $10^{\circ}$. Os resultados foram determinados a partir do sistema Hunterlab (L, a e b).

\subsubsection{Análises microbiológicas}

A contagem de bolores e leveduras foi feita pelo método de plaqueamento em superfície em meio ágar batata dextrose (Fluka, EUA) acidificado com ácido tartárico (Dinâmica, São Paulo) e posterior incubação a $25^{\circ} \mathrm{C}$ por 5 dias (SILVA et al., 2007). 
A contagem de mesófilos foi realizada em ágar padrão - PCA (Merck, Brasil) por plaqueamento em profundidade, com incubação a $35^{\circ} \mathrm{C}$ por 48 horas (SILVA et al., 2007). Todos os resultados das contagens foram expressos em log UFC/g.

\subsection{ANÁLISE ESTATÍSTICA}

Os resultados obtidos foram analisados por análise de variância (ANOVA) pelo programa STATISTICA 7 e as médias dos tratamentos comparadas pelo teste de Tukey ao nível de $5 \%$ de significância $(p<0,05)$.

\section{RESULTADOS E DISCUSSÃO}

\subsection{MEDIDA DO PH}

A Figura 1 apresenta os valores médios de $\mathrm{pH}$ dos brócolis minimamente processados, com diferentes tratamentos e armazenados durante 10 dias sob refrigeração. $\mathrm{O} \mathrm{pH}$ inicial dos brócolis minimamente processado foi de 5,97 . Valor próximo $(6,08)$ foi relatado por Padula et al. $(2006)$ em brócolis orgânico minimante processado.

Avaliando o efeito do tratamento, notou-se que no terceiro e no sexto dia de armazenamento os valores de $\mathrm{pH}$ dos brócolis revestidos com quitosana foram estatisticamente menores. Valores elevados de pH podem estar associados com a utilização de ácidos orgânicos em excesso como substrato respiratório. Desta forma, pode-se deduzir que o revestimento de quitosana pode ter atuado como uma barreira, impedindo a difusão de oxigênio e assim reduziu a taxa de respiração.

Considerando o tempo de armazenamento, não notou-se grande variação nos valores de $\mathrm{pH}$ para os diferentes tratamentos. Comportamento semelhante foi observado por e Velickova et al. (2013) onde o pH se manteve estável durante o armazenamento de melão minimamente processado com revestimento de quitosana e adicionado de óleo essencial.

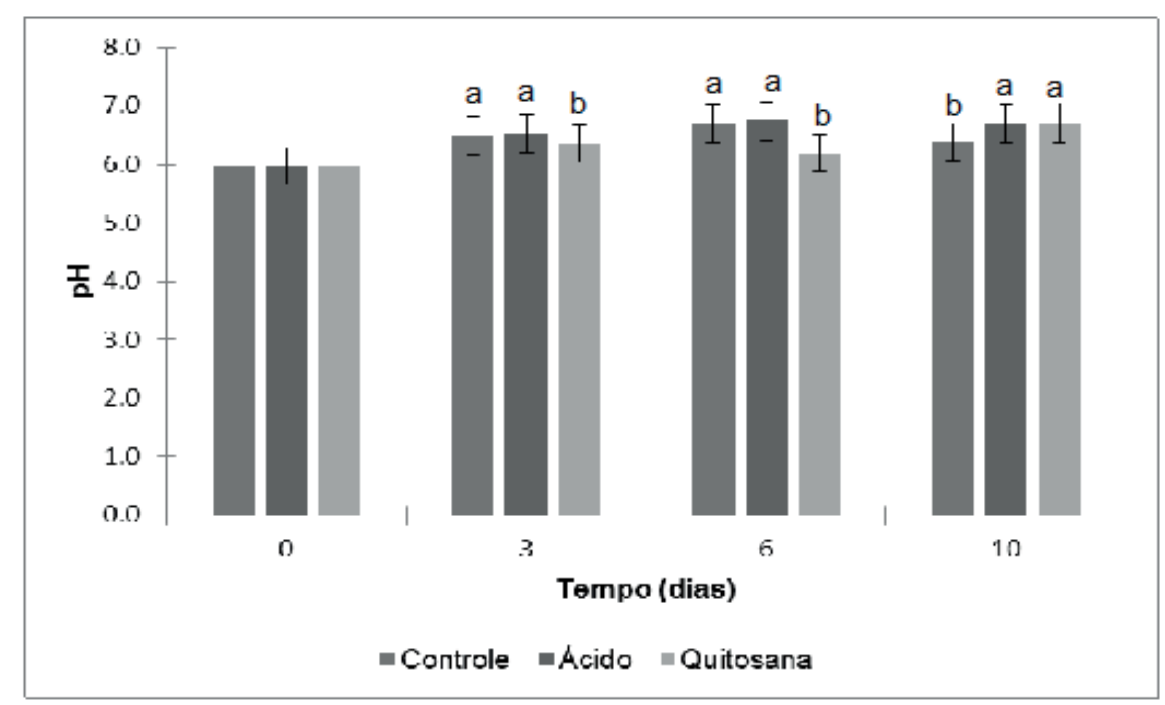

\section{FIGURA 1 - VALORES DE PH DOS BRÓCOLIS MINIMAMENTE PROCESSADOS COM DIFERENTES TRATAMENTOS E ARMAZENADOS SOB REFRIGERAÇÃO.}




\subsection{PERDA DE MASSA}

A Figura 2 apresenta a perda de massa dos brócolis minimamente processados, com diferentes tratamentos durante o armazenamento refrigerado. Este parâmetro de qualidade é importante, pois a perda de massa está relacionada com perdas econômicas. Além disso, a perda de massa causa o encolhimento dos brócolis, causando um impacto negativo na aparência dos mesmos (ANSORENA; MARCOVICH; ROURA, 2011).

Durante o armazenamento houve um aumento gradativo na percentagem de perda de massa e após o sexto dia os brócolis revestidos com quitosana apresentaram menor valor, quando comparado aos demais tratamentos. A redução na perda de massa das amostras revestidas com quitosana pode estar ligada à presença da cobertura na superfície do produto que reduziu a permeabilidade ao vapor de água do produto para o ambiente e também esta atuou como uma barreira para permeabilidade do oxigênio, reduzindo a taxa de respiração. Resultados semelhantes foram observados em brócolis minimamente processado revestidos com quitosana e carboximetilcelulose (ANSORENA; MARCOVICH; ROURA, 2011) e em aspargos revestidos com quitosana de diferentes massas moleculares (QIU et al.,2013).

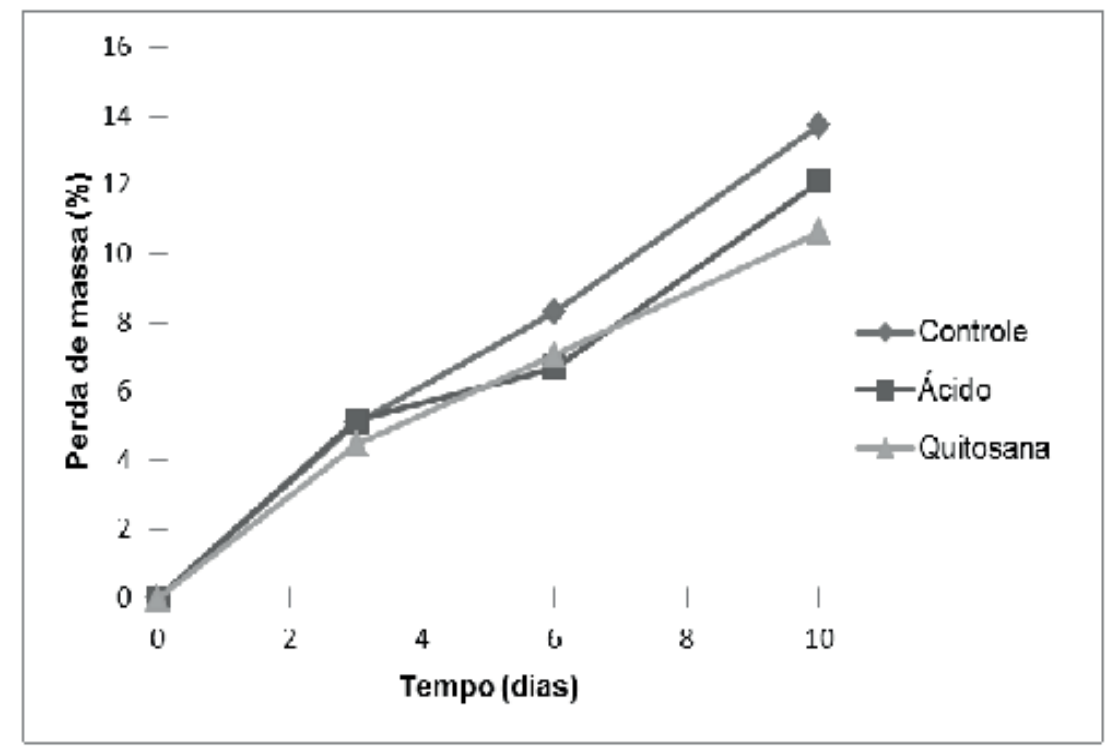

\section{FIGURA 2 - PERDA DE MASSA EM BRÓCOLIS MINIMAMENTE PROCESSADO COM DIFERENTES TRATAMENTOS DURANTE O ARMAZENAMENTO REFRIGERADO.}

\subsection{TEOR DE ÁCIDO ASCÓRBICO}

A variação do teor do ácido ascórbico dos brócolis minimamente processados, contendo diferentes tratamentos durante o armazenamento refrigerado está apresentada na Figura 3. $\mathrm{O}$ teor inicial de ácido ascórbico foi de 118,42 mg/100 g de brócolis. Valores inferiores $(78 \mathrm{mg} / 100 \mathrm{~g})$ foram reportados por Ansorena, Marcovich e Roura (2011) e valores maiores ( 150 mg/100 g) por Yamashita et al. (2006) em brócolis ramoso minimamente processado.

Ao longo do armazenamento todas as amostras apresentaram redução no teor de ácido ascórbico, sendo que este fenômeno está fortemente ligado à presença de oxigênio (QIU et al.,2013). As amostras revestidas com quitosana tiveram uma menor perda em relação ao controle, indicando que a incorporação de revestimento a base deste polímero reduziu a difusão de oxigênio 
preservando o conteúdo de ácido ascórbico. Comportamento similar foi observado em aspargos (QIU et al., 2013), em mangas (CHIEN; SHEU; YANG, 2007) e brócolis minimamente processado (ANSORENA, MARCOVICH, ROURA, 2011) revestidos com quitosana.

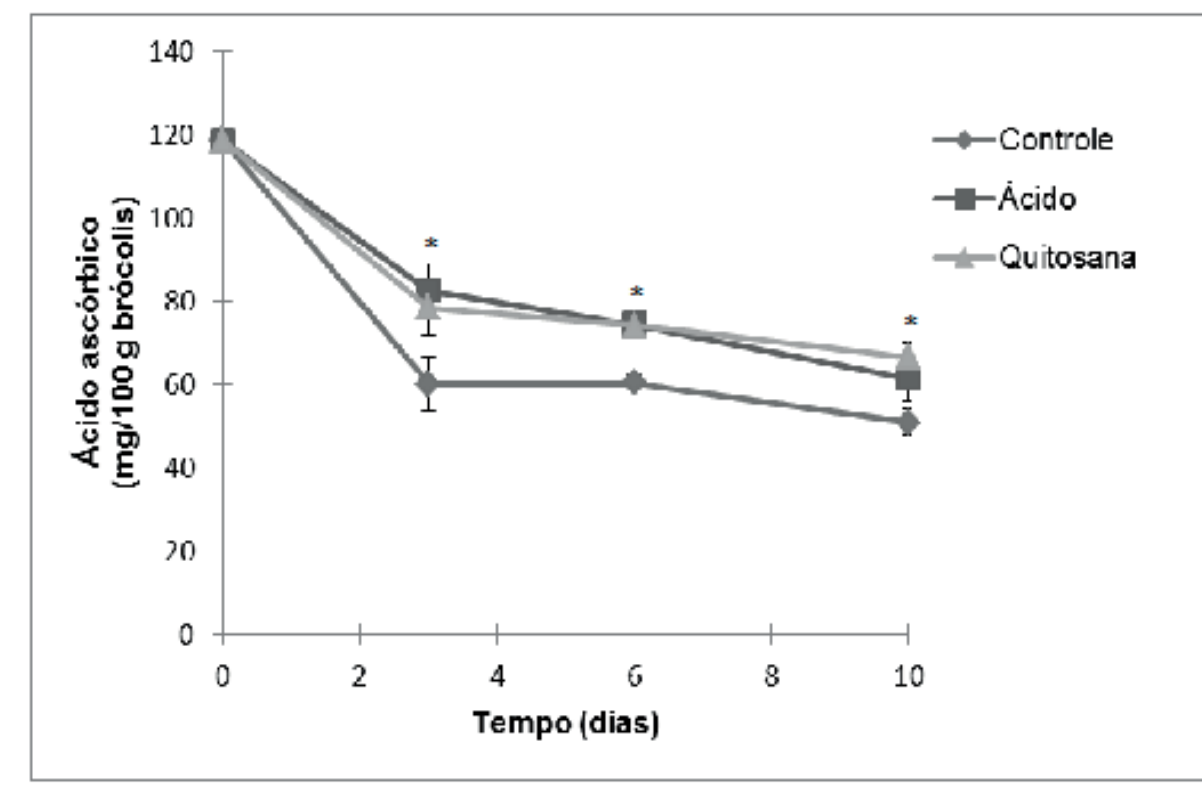

\section{FIGURA 3 - TEOR DE ÁCIDO ASCÓRBICO EM BRÓCOLIS MINIMAMENTE PROCESSADO COM DIFERENTES TRATAMENTOS DURANTE O ARMAZENAMENTO REFRIGERADO. *}

Apresentam diferença significativa em relação ao controle ao nível de $5 \%(P<0,05)$ pelo teste de Tukey.

\subsection{MEDIDA DE COR}

A cor é um atributo importante para o brócolis e o amarelecimento a que ele está sujeito é o termo usado para descrever a condição adversa da qualidade do produto, resultante da degradação da clorofila. Esse processo inclusive, tem sido utilizado como indicador e como uma ferramenta para avaliar a qualidade e predizer a sua vida útil (TOIVONEN; DEELL, 2001).

Os parâmetros de cor, expressos em termos de $\mathrm{L}$, a e b, dos brócolis minimamente processados medidos durante o armazenamento refrigerado estão resumidos na Tabela 1. $O$ parâmetro $L$ está relacionado com a luminosidade, ou seja, quanto maior o valor de $L$, mais clara é a amostra e quanto menor, mais escura é a amostra. O valor de "a" indica cor verde quando negativo e cor vermelho quando positivo. Já o valor "b" quando negativo representa a cor azul e quando positivo a cor amarelo. Após 10 dias de armazenamento, o valor de $L$ aumentou para todos os tratamentos, correspondendo a um clareamento das amostras. É possível que isto possa estar relacionado com o descoloramento dos brócolis, ou seja, a clorofila foi degradada deixando as amostras mais brancas. Este fato também pode ser comprovado pelos valores de -a, que decaíram com o tempo. Por outro lado, o valor de b manteve-se estável indicando que não houve amarelamento dos floretes.

Ao avaliar o efeito do tratamento, de uma forma geral, durante o armazenamento os parâmetros de cor não apresentaram variação significativa $(p<0,05)$. Resultados diferentes foram verificados por Ansorena, Marcovich e Roura (2011), onde os brócolis revestidos com quitosana e carboximetilcelulose mantiveram a cor verde e a degradação de clorofila ocorreu em menor proporção quando comparado com as amostras controle. 


\section{TABELA 1 - PARÂMETROS DE COR EM BRÓCOLIS MINIMAMENTE PROCESSADO COM DIFERENTES TRATAMENTOS DURANTE O ARMAZENAMENTO REFRIGERADO.}

\begin{tabular}{|c|c|c|c|c|}
\hline & 0 & 3 dias & 6 dias & 10 dias \\
\hline \multicolumn{5}{|l|}{$\mathbf{L}$} \\
\hline Controle & $29,90 \pm 2,86^{\mathrm{B}}$ & $41,09 \pm 3,20^{\mathrm{aA}}$ & $36,44 \pm 5,04^{\mathrm{aA}}$ & $41,17 \pm 6,63^{\mathrm{aA}}$ \\
\hline Ácido & $29,90 \pm 2,86^{\mathrm{B}}$ & $38,25 \pm 2,80^{\mathrm{abA}}$ & $23,46 \pm 5,34^{\mathrm{bc}}$ & $41,78 \pm 4,19^{\mathrm{aA}}$ \\
\hline Quitosana & $29,90 \pm 2,86^{\mathrm{B}}$ & $37,25 \pm 2,95^{\mathrm{bA}}$ & $22,36 \pm 7,67^{\mathrm{bC}}$ & $37,19 \pm 6,62^{\mathrm{aA}}$ \\
\hline \multicolumn{5}{|l|}{ a } \\
\hline Controle & $-9,38 \pm 1,38^{A}$ & $-6,42 \pm 1,02^{\mathrm{aB}}$ & $-8,76 \pm 1,79^{\mathrm{aA}}$ & $-6,75 \pm 1,68^{\mathrm{aB}}$ \\
\hline Ácido & $-9,38 \pm 1,38^{A}$ & $-6,11 \pm 0,94^{\mathrm{aB}}$ & $-9,70 \pm 1,39^{\mathrm{aA}}$ & $-5,55 \pm 0,99^{\mathrm{aB}}$ \\
\hline Quitosana & $-9,38 \pm 1,38^{A}$ & $-6,15 \pm 0,88^{a B}$ & $-10,14 \pm 2,96^{\mathrm{aA}}$ & $-5,27 \pm 1,48^{\mathrm{aB}}$ \\
\hline \multicolumn{5}{|l|}{ b } \\
\hline Controle & $33,02 \pm 6,81^{\mathrm{A}}$ & $19,59 \pm 3,91^{\mathrm{aB}}$ & $32,35 \pm 9,55^{\mathrm{aA}}$ & $28,02 \pm 2,35^{\mathrm{aA}}$ \\
\hline Ácido & $33,02 \pm 6,81^{A B}$ & $21,37 \pm 5,04^{\mathrm{ac}}$ & $39,32 \pm 8,49^{\mathrm{aA}}$ & $27,60 \pm 4,43^{\mathrm{aBC}}$ \\
\hline Quitosana & $33,02 \pm 6,81^{\mathrm{AB}}$ & $22,96 \pm 3,26^{\mathrm{ac}}$ & $37,70 \pm 12,0^{\mathrm{aA}}$ & $26,18 \pm 4,23^{\mathrm{aBC}}$ \\
\hline
\end{tabular}

Letras minúsculas na coluna e letras maiúsculas na linha iguais não apresentam diferença significativa ao nível de $5 \%$ $(p<0,05)$ pelo teste de Tukey.

\subsection{CONTAGEM DE MESÓFILOS E BOLORES E LEVEDURAS}

As contagens de mesófilos e de bolores e leveduras estão apresentadas na Tabela 2. A contagem inicial de mesófilos do brócolis foi de 2,41 log UFC/g. Contagem maior (4,34 log UFC/g) foi obtido por Ansorena, Marcovich e Roura (2011) em brócolis minimamente processado. Para todos os tratamentos foi observado uma elevação na contagem total de mesófilos e de bolores e leveduras durante os 10 dias de armazenamento refrigerado. Apenas no $6^{\circ}$ dia de armazenamento as amostras revestidas com quitosana e as tratadas com ácido apresentaram contagem significativamente menor.

\section{TABELA 2 - CONTAGEM DE MESÓFILOS E BOLORES E LEVEDURAS EM BRÓCOLIS MINIMAMENTE PROCESSADO DURANTE O ARMAZENAMENTO REFRIGERADO.}

\begin{tabular}{|c|c|c|c|c|c|c|}
\hline \multirow[b]{2}{*}{ Tempo } & \multicolumn{3}{|c|}{ Mesófilos (log UFC/g) } & \multicolumn{3}{|c|}{ Bolores e Leveduras (log UFC/g) } \\
\hline & Controle & Ácido & Quitosana & Controle & Ácido & Quitosana \\
\hline 0 & $2,41 \pm 0,36$ & $2,41 \pm 0,36$ & $2,41 \pm 0,36$ & $1,00 \pm 0,01$ & $1,00 \pm 0,01$ & $1,00 \pm 0,01$ \\
\hline 3 & $6,15 \pm 0,47^{\mathrm{a}}$ & $5,18 \pm 0,31^{b}$ & $5,85 \pm 0,01^{a}$ & $5,65 \pm 0,07^{\mathrm{ab}}$ & $4,78 \pm 0,49^{b}$ & $5,81 \pm 0,25^{a}$ \\
\hline 6 & $6,77 \pm 0,04^{a}$ & $6,41 \pm 0,11^{b}$ & $6,11 \pm 0,14^{b}$ & $6,28 \pm 0,10^{\mathrm{a}}$ & $5,00 \pm 0,01^{\mathrm{b}}$ & $5,54 \pm 0,28^{b}$ \\
\hline 10 & $6,80 \pm 0,01^{a}$ & $6,80 \pm 0,01^{a}$ & $6,78 \pm 0,04^{a}$ & $6,60 \pm 0,33^{a}$ & $5,85 \pm 0,18^{b}$ & $5,10 \pm 0,02^{c}$ \\
\hline
\end{tabular}

a, b, c letras iguais na linha não apresentam diferença significativa ao nível de $5 \%(p<0,05)$ pelo teste de Tukey. 
Segundo Dutta et al.(2009) a quitosana com alto teor de desacetilação tem maior caráter antimicrobiano que as com alto grau de grupos aminos acetilados. A ação antimicrobiana da quitosana contra bactérias pode ser devido a grande quantidade de cargas positivas na molécula devido a desacetilação que permite a interação e formação de complexos polieletrolíticos com os polímeros da superfície da célula bacteriana (DURANGO; SOARES; ANDRADE, 2006).

Para a contagem de bolores e leveduras, os brocolis revestidos com quitosana apresentaram valores estatisticamente menores a partir do $6^{\circ}$ dia de armazenamento, comprovando o efeito antifúngico da quitosana. As amostras tratadas com ácido tiveram menores contagens, provavelmente, devido à atividade antimicrobiana do ácido acético que desfavoreceu o desenvolvimento de bolores e leveduras.

O mecanismo de ação da quitosana contra fungos envolve a interação do polissacarídeo com a parede celular do microrganismo interferindo diretamente em seu crescimento. Além disso, os oligômeros de quitosana se difundem dentro das hifas fúngicas interferindo na atividade das enzimas responsáveis pelo crescimento do fungo. A intensidade de ação de degradação da parede celular dos fungos é dependente do $\mathrm{pH}$ do meio, do grau de desacetilação da quitosana e da concentração desse polímero (GOY et al., 2009).

Ao contrário do relatado em outros trabalhos (ANSORENA; MARCOVICH; ROURA, 2011; MOREIRA; ROURA; PONCE, 2011) a quitosana não atuou de forma efetiva contra micorganismos mesófilos, mas apresentou atividade antimicrobiana contra bolores e leveduras. A diferença pode estar relacionada com o grau de desacetilação e massa molecular da quitosana. Enquanto no presente estudo utilizou-se quitosana de baixa massa molecular com $85 \%$ de grau de desacetilação, nos outros trabalhos a quitosana foi de média massa molecular com $98 \%$ de grau de desacetilação.

\section{CONCLUSÃO}

O revestimento comestível a base de quitosana se mostrou efetivo quando aplicado em brócolis minimamente processado, pois reduziu as perdas de ácido ascórbico, inibiu o desenvolvimento de bolores e leveduras e diminuiu a perda de massa ao longo do armazenamento refrigerado. Desta forma, a quitosana pela sua atividade antifúngica e por ser um polímero biodegradável e biocompatível poderia ser uma alternativa para auxiliar na conservação de vegetais minimamente processados em escala comercial.

\section{ABSTRACT}

\section{APPLICATION OF CHITOSAN EDIBLE COATING IN FRESH CUT BROCCOLI}

Minimal processament offers convenience to a wide variety of vegetables such as broccoli. However, cutting and slicing operations cause tissue damage that increase susceptibility to microbiological contamination and respiration rate. Edible coatings based on biopolymers have been studied in order to assist the conservation of fresh-cut vegetables. This study aimed to apply chitosan based edible coating in minimally processed broccoli and evaluate their shelf-life during 10 days of refrigerated storage. Physicochemical and microbiological analyses such as color, $\mathrm{pH}$, weight loss, ascorbic acid content, mesophilic and molds and yeasts count were performed. The minimally processed broccoli coated with chitosan showed less weight loss and higher ascorbic acid content, in addition to inhibit the growth of molds and yeasts. The results of this work suggest that chitosan has great potential to be applied as edible coating on minimally processed vegetables in commercial scale.

KEY-WORDS: BIOPOLYMER. ANTIMICROBIAL ACTIVITY. SHELF-LIFE. ASCORBIC ACID. 


\section{REFERÊNCIAS}

1 ALVAREZ, M. V.; PONCE, A. G.; MOREIRA, M. R. Antimicrobial efficiency of chitosan coating enriched with bioactive compounds to improve the safety of fresh cut broccoli. LWT - Food Science and Technology, v. 50, p. 78-87, 2013.

2 ANSORENA, M. R.; MARCOVICH, N. F.; ROURA, S. I. Impact of edible coatings and mild heat shocks on quality of minimally processed broccoli (Brassica oleracea L.) during refrigerated storage. Postharvest Biology and Technology, v. 59, p. 53-63, 2011.

3 APPENDINI, P.; HOTCHKISS, J. H. Review of antimicrobial food packaging. Innovative Food Science \& Emerging Technologies, v. 3, p. 113-126, 2002.

4 ASSIS, O. B. G.; FORATO, L. A.; BRITTO, D. Revestimentos comestíveis protetores em frutos minimamente processados. Higiene Alimentar, v. 22, n. 160, p. 99-106, 2008.

5 ASSIS, O. B. G.; BRITTO, D. Coberturas comestíveis protetoras em frutas: fundamentos e aplicações. Brazilian Journal of Food Technology, v. 17, n. 2, p. 87-97, 2014.

6 BENASSI, M. T.; ANTUNES, A. J. A comparison of metaphosphoric and oxalic acids as extractants solutions for the determination of vitamin $C$ in selected vegetables. Brazilian Archives of Biology and Technology, v. 31, n. 4, p. 507513, 1988.

7 CENSI, S. A. Processamento mínimo de frutas e hortaliças: Tecnologia, qualidade e sistemas de embalagem. Rio de Janeiro: Embrapa Agroindústria de Alimentos, 2011, 144 p.

8 CHIEN, P.; SHEU, F.; YANG, F. Effects of edible chitosan coating on quality and shelf life of sliced mango fruit. Journal of Food Engineering, v. 78, p. 225-229, 2007.

9 CHITARRA, M. I. F.; CHITARRA, A. B. Pós-colheita de frutas e hortaliças: fisiologia e manuseio. 2 ed. Lavras: UFLA, 2005.

10 DUTTA, P.; TRIPATHI, S.; MEHROTRA, G.; DUTTA, J. Review: perspectives for chitosan based antimicrobial films in food aplications. Food Chemistry, v.114, p.1173-1182, 2009.

11 DURANGO, A.; SOARES, N.; ANDRADE, N. Microbiological evaluation of an edible antimicrobial coating on minimally processed carrots. Food Control, v.17, p. 336-341, 2006.

12 FILGUEIRA, F. A. R. Novo Manual de Olericultura: agrotecnologia moderna na produção e comercialização de hortaliças. Viçosa: UFV, 2000, $402 \mathrm{p}$.

13 IAL. Métodos físico-químicos para análise de alimentos. 1. ed. digital. São Paulo, 2008.

14 LEMOINE, M. L.; CIVELLO, P.; CHAVES, A.; MARTINEZ, G. Hot air treatments delasenescence and maintains quality of fresh-cut broccoli florets during refrigerated storage. LWT - Food Science and Technology, v. 42, p.1076-1181, 2009.

15 MOREIRA, M.; ROURA, S.; PONCE, A. Effectiveness of chitosan edible coatings to improve microbiological and sensory quality of fresh cut broccoli. LWT - Food Science and Technology, v. 44, p. 2335-2341, 2011.

16 PADULA, M. L.; CARCIOFI, B. A. M.; DANNENHAUER, C. E.; STRINGARI, G. B.; MONTEIRO, A. R. Influência de diferentes tipos de embalagem nas características físico-químicas e composição gasosa de brócolis (Brassica oleracea L. var. Itálica) orgânicos minimamente processados e armazenados sob refrigeração. Alimentos e Nutrição, v. 17, n. 3, p. 259-268, 2006.

17 PAGE, T.; GRIFFITHS, G.; BUCHANAN-WOLLASTON, V. Molecular and bio-chemical characterization of postharvest senescence in broccoli. Plant Physiology, v.125, p.718-727, 2001.

18 PARK, S.; DAESCHEL, M.; ZHAO, Y. Functional properties of antimicrobial lysozyme-chitosan composite films. Journal of Food Science, v. 69, p. 215-221, 2004.

19 PARK, H. J. Edible coatings for fruits. In: JONGEN, W. W. F. (Ed.). Fruit and vegetable processing: improving quality. Boca Raton: CRC Press, 2005. p. 331-345.

20 PEREIRA, T.; CARLOS, L. A.; OLIVEIRA, J. G.; MONTEIRO, A. R. Características físicas e químicas de goiaba cv. Cortibel (Psidium guajava) estocadas sob refrigeração em filmes x-tend. Alimentos e Nutrição, v. 16, n. 1, p. 11-16, 2005.

21 PORTE, A.; MAIA, L. H. Alterações fisiológicas, bioquímicas e microbiológicas de alimentos minimamente processados. Boletim do Ceppa, v. 19, n. 1, p. 105-118, 2001.

22 QIU, M.; JIANG, H.; REN, G.; HUANG, J.; WANG, X. Effect of chitosan coating on postharvest green asparagus quality. Carbohydrate Polymers, v. 92, p. 2027-2032, 2013.

23 SILVA, N.; JUNQUEIRA, V. C. A.; SILVEIRA, N. F. A.; TANIWAKI, M. H.; SANTOS, R. F. S.; GOMES, R. A. R. Manual de 
métodos de análise microbiológica de alimentos. São Paulo: Varela, 3 ed, 2007, 552p.

24 TOIVONEN, P. M. A.; DEELL, J. R. Chlorophyll fluorescence, fermentation product accumulation, and quality of stored broccoli in modified atmosphere packages and subsequent air storage. Postharvest Biology and Technology, v. 23, n. 1, p. 61-69, 2001

25 TURHAN, K. N. Is edible coating an alternative to MAP for fresh and minimally processed fruits? Acta Horticulturae, v. 876, n. 1, p. 299-305, 2010.

26 VALLEJO, F.; GARCÍA-VIGUERA, C.; TOMÁS-BARBERÁN, F. Health-promoting compounds in broccoli as influenced by refrigerated transport and retail sale period. Journal of Agricultural and Food Chemistry, 51, p. 3029-3034, 2003.

27 VELICKOVA, E.; WINKELHAUSEN, E.; KUZMANOVA, D.; ALVES, V. D. Impact of chitosan-beeswax edible coatings on the quality of fresh strawberries (Fragaria ananassa cv Camarosa) under commercial storage conditions. Food Science and Technology, v. 52, p. $80-90,2013$.

28 YAMASHITA, F. MATIAS, A. N.; GROSSMANN, M. V. E.; ROBERTO, S. R.; BENASSI, M. T. Active packaging for freshcut broccoli using 1-methylcyclopropene in biodegradable sachet. Semina: Ciências Agrárias, v. 27, n.4, p. 581-586, 2006.

\section{AGRADECIMENTOS}

Os autores agradecem ao CNPq pelo auxílio financeiro. 